\title{
Reduced Graphene Oxide Wrapped Sulfur/Polypyrrole Composite Cathode with Enhanced Cycling and Rate Performance for Lithium/Sulfur Batteries
}

\author{
Guanghui Yuan ${ }^{1 *}$, Huafeng Jin ${ }^{1}$, Yan Zhao ${ }^{2 *}$ \\ ${ }^{1}$ School of Chemistry and Chemical Engineering, Research Centre of New Materials, Ankang \\ Research Centre of Zn Based Materials Science and Technology, Ankang University, Shaanxi Ankang, \\ China \\ ${ }^{2}$ Synergy Innovation Institute of GDUT, Heyuan, Guangdong Province, China \\ *E-mail: chem_yuan@163.com; zhaoyan_sii@163.com
}

doi: $10.20964 / 2019.02 .45$

Received: 24 August 2018 / Accepted: 19 November 2018 / Published: 5 January 2019

\begin{abstract}
An innovative reduced graphene oxide wrapped sulfur/polypyrrole (S/PPy@RGO) composite is synthesized via a one-pot polymerization of pyrrole monomer in a sulfur/reduced graphene oxide aqueous suspension. This one-pot preparation method is efficient through its inherent simplicity and low cost. The resultant S/PPy@RGO composite was characterized via EDS, XRD, SEM, TEM and electrochemical measurements. In the S/PPy@RGO ternary composite, reduced graphene oxide played a crucial role of coating a thin layer to trap soluble polysulfide intermediates, provide a continuous electrically conducting network and accommodate volume expansion. Meanwhile polypyrrole with its high absorptivity, joins sulfur and RGO as a binding agent, and tether polysulfides into its porous framework. Therefore, the synthesized S/PPy@RGO composite delivers excellent rate ability and highly cycling stability. This composite can retain a specific discharge capacity of $615.3 \mathrm{mAh} \mathrm{g}^{-1}$ at $0.2 \mathrm{C}$, even after 100 cycles.
\end{abstract}

Keywords: S/PPy@RGO composite; one pot polymerization; lithium/sulfur batteries; electrochemical performance

\section{$\underline{\text { FULL TEXT }}$}

(C) 2019 The Authors. Published by ESG (www.electrochemsci.org). This article is an open access article distributed under the terms and conditions of the Creative Commons Attribution license (http://creativecommons.org/licenses/by/4.0/). 